\title{
Long-term oral exposure to bisphenol A induces glucose intolerance and insulin resistance
}

\author{
Min Kyong Moon 1,2,", In-Kyong Jeong ${ }^{1, *}$, Tae Jung Oh', Hwa Young Ahn ${ }^{1,3}$, Hwan Hee \\ $\mathrm{Kim}^{4}$, Young Joo Park', Hak Chul Jang ${ }^{1,5}$ and Kyong Soo Park \\ ${ }^{1}$ Department of Internal Medicine, Seoul National University College of Medicine, 101 Daehak-ro, Jongno-gu, \\ Seoul 110-744, Republic of Korea \\ ${ }^{2}$ Department of Internal Medicine, Boramae Medical Center, Seoul 156-707, Republic of Korea \\ ${ }^{3}$ Department of Internal Medicine, Chung-Ang University Hospital, College of Medicine, Chung-Ang University, \\ Seoul 156-755, Republic of Korea \\ ${ }^{4}$ Clinical Research Institute, Seoul National University Hospital, Seoul 110-74, Republic of Korea \\ ${ }^{5}$ Department of Internal Medicine, Seoul National University Bundang Hospital, Seongnam 463-707, \\ Republic of Korea \\ ${ }^{*}$ (M K Moon and I-K Jeong contributed equally to this work)
}

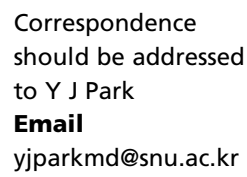

yjparkmd@snu.ac.kr

\begin{abstract}
Bisphenol A (BPA) is a widely used endocrine disruptor. Recent epidemiologic results have suggested an association between exposure to BPA and cardiovascular disease, type 2 diabetes, and obesity. We investigated the in vivo effects of long-term oral exposure to BPA on insulin resistance and glucose intolerance. In the present study, 4- to 6-week-old male mice on a high-fat diet (HFD) were treated with $50 \mu \mathrm{g} / \mathrm{kg}$ body weight per day of BPA orally for 12 weeks. Long-term oral exposure to BPA along with an HFD for 12 weeks induced glucose intolerance in growing male mice. Intraperitoneal glucose tolerance tests showed that the mice that received an HFD and BPA exhibited a significantly larger area under the curve than did those that received an HFD only (119.9 \pm 16.8 vs $97.9 \pm 18.2 \mathrm{mM} / \mathrm{min}, P=0.027)$. Body weight, percentage of white adipose tissue, and percentage of body fat did not differ between the two groups of mice. However, treatment with BPA reduced Akt phosphorylation at position Thr308 and GSK3 $\beta$ phosphorylation at position Ser9 in skeletal muscle. BPA tended to decrease serum adiponectin levels and to increase serum interleukin 6 and tumor necrosis factor $\alpha$, although these findings were not statistically significant. Treatment with BPA did not induce any detrimental changes in the islet area or morphology or the insulin content of $\beta$ cells. In conclusion, long-term oral exposure to BPA induced glucose intolerance and insulin resistance in growing mice. Decreased Akt phosphorylation in skeletal muscle by way of altered serum adipocytokine levels might be one mechanism by which BPA induces glucose intolerance.
\end{abstract}

\author{
Key Words \\ - bisphenol A \\ - glucose intolerance \\ - insulin resistance \\ - skeletal muscle \\ - adipocytokine
}

Journal of Endocrinology (2015) 226, 35-42

\section{Introduction}

Bisphenol A (BPA) is a base material for the production of polycarbonate plastic and epoxy resin, and it is a widely used chemical (Brotons et al. 1995, Olea et al. 1996). BPA is a well-known endocrine disruptor and has a weak estrogenic effect that is 100 - to 10000 -fold lower than that of $17 \beta$-estradiol. The adverse effects of BPA seem to be

Published by Bioscientifica Ltd 
largely related to its estrogenic activity (Hiroi et al. 1999, Kurosawa et al. 2002), and they can result in disturbances of reproductive function. However, recent epidemiologic evidence has also implicated BPA in cardiovascular disease, type 2 diabetes, and obesity: increasing serum or urine BPA levels have been positively associated with diabetes mellitus (Lang et al. 2008, Shankar \& Teppala 2011), cardiovascular disease (Lang et al. 2008), obesity, and insulin resistance (Wang et al. 2012). Several possible mechanisms have been suggested by animal and in vitro studies, yet whether BPA causes insulin resistance or diabetes is still controversial.

Several studies in rodent models have reported that perinatal exposure to BPA increases the body weight of offspring at 6 months of age (Alonso-Magdalena et al. 2010) and in adulthood (Somm et al. 2009) as well as in the neonatal period (Howdeshell et al. 1999, Rubin et al. 2001, Rubin \& Soto 2009). However, Ryan et al. (2010) reported a contrary result that oral exposure to BPA during the perinatal period did not induce glucose intolerance later in life in CD-1 mice. Data on whether exposure to BPA after birth induces glucose intolerance are more limited. A single low dose of BPA $(10 \mu \mathrm{g} / \mathrm{kg})$ and 4 or 8 days of injected $100 \mu \mathrm{g} / \mathrm{kg}$ BPA have been shown to induce insulin resistance and glucose intolerance in adult male mice (Alonso-Magdalena et al. 2006, Batista et al. 2012).

Several mechanisms have been proposed to explain the effect of BPA on glucose intolerance, including the disturbance of pancreatic $\beta$ cell function (Nadal et al. 2000, Alonso-Magdalena et al. 2006), decreased production or secretion of adiponectin from adipocytes, the establishment of insulin-sensitizing adipocytokine (Hugo et al. 2008, Kidani et al. 2010), enhanced adipocyte differentiation and lipid accumulation (Masuno et al. 2002, 2005, Somm et al. 2009, Ohlstein et al. 2014), and increased insulin resistance resulting from increased oxidative stress and mitochondrial dysfunction (Nakagawa \& Tayama 2000, Bindhumol et al. 2003, Asahi et al. 2010, Moon et al. 2012).

Accordingly, exposure to BPA seems to be able to contribute to the development of insulin resistance and diabetes. However, it is still unclear whether long-term oral exposure to BPA after the neonatal period induces insulin resistance and glucose intolerance.

In the present study, we investigated the effects of long-term exposure to BPA using a diet-induced obesity mouse model, and we demonstrated that BPA exposure in the postnatal and adult periods can increase insulin resistance and glucose intolerance in vivo.

\section{Materials and methods}

\section{Animals}

C57BL/6 male mice were purchased from Orient (Seongnam, Korea). The mice were acclimatized to the laboratory environment for at least 1 week before the experiments commenced. They were then divided into four groups: i) standard mouse chow diet (CD); ii) high-fat diet (HFD); iii) CD with BPA; and iv) HFD with BPA. The CD comprised $\sim 3.6 \mathrm{kcal} / \mathrm{g}$, with $21 \%$ protein, $12.5 \% \mathrm{fat}$, and $66.5 \%$ carbohydrates. The HFD comprised $\sim 5.0 \mathrm{kcal} / \mathrm{g}$, with $21 \%$ protein, $66.5 \%$ fat, and $12.5 \%$ carbohydrates (Bi et al. 2007). BPA (purity $>99 \%$ ) was purchased from Wako Pure Chemical Industries (Sigma-Aldrich). BPA was mixed with $30 \%$ ethanol and diluted in water to the appropriate concentrations for the experiments.

Four- to 6-week-old mice were treated with BPA dissolved in water at $50 \mu \mathrm{g} / \mathrm{kg}$ body weight (bw) per day orally for 12 weeks. Each group included five mice, and the experiment was repeated at least three times. All of the mice were housed in conventional plastic cages at $23 \pm$ $2{ }^{\circ} \mathrm{C}$ and $60 \pm 10 \%$ humidity; a $12 \mathrm{~h}$ light: $12 \mathrm{~h}$ darkness cycle was used, and the mice had free access to water. After 12 weeks of feeding with the assigned diet, the mice were killed for tissue sampling after $8 \mathrm{~h}$ of fasting. Epididymal fat (white adipose tissue, WAT), liver tissue, and skeletal muscle (gastrocnemius) were isolated, freeze-clamped in liquid nitrogen immediately after being weighed, and stored at $-80^{\circ} \mathrm{C}$ until the assays were performed. The pancreas was immediately isolated for histologic examination and fixed in 10\% formaldehyde for $24-48 \mathrm{~h}$. For transmission electron microscopic examination, pancreatic tissues were dissected, cut into small sections $(1 \times$ $1 \mathrm{~mm}$ ), and immersed in $2.5 \%$ glutaraldehyde at $4{ }^{\circ} \mathrm{C}$. All of the procedures that involved the use of laboratory animals were in accordance with the Guide for Standard Operation Procedures and were approved by the Institutional Animal Care and Use Committee of the Clinical Research Institute, Seoul National University Bundang Hospital (approval number BA1103-079/021-01).

\section{Body weight and fat mass measurements and glucose tolerance tests}

Body weight and food consumption were measured every 3 days during the experiments. Before they were killed, the animals' total body fat content was measured using dual-energy X-ray absorptiometry (GE Lunar PIXImus, Fitchburg, WI, USA) under anesthesia. The epididymal fat

Published by Bioscientifica Ltd 
pads were surgically removed through a mid-abdominal incision, and the weight of each dissected fat mass was recorded immediately.

To assess glucose homeostasis, an intraperitoneal glucose tolerance test (IPGTT) was performed at the beginning and end of each experiment. After overnight fasting, the mice were injected intraperitoneally with $2 \mathrm{~g} / \mathrm{kg}$ glucose; blood samples were collected from their tails $0,30,60$, 90, and 120 min later. Glucose levels were measured by a glucometer (ACCU-CHEK Active, Roche).

\section{Measurement of insulin, adiponectin, and cytokine levels}

Serum samples from the mice were maintained at $-80{ }^{\circ} \mathrm{C}$ until analysis. Serum and islet insulin levels were measured by a RIA kit (LINCO Research, St Charles, MO, USA) according to the manufacturer's instructions. Adiponectin, interleukin 6 (IL6) and tumor necrosis factor $\alpha(\mathrm{TNF} \alpha)$ levels were measured by an ELISA kit according to the manufacturer's instructions (Adipogen, Seoul, Korea; R\&D Systems, Minneapolis, MN, USA).

\section{Protein analysis}

Skeletal muscle tissues were homogenized in lysis buffer (Cell Signaling Technology, Danvers, MA, USA), and the protein concentration was determined by a protein assay kit (Pierce Biotechnology, Rockford, IL, USA). Protein $(12 \mu \mathrm{g})$ was mixed with gel loading buffer containing $62.5 \mathrm{mM}$ Tris- $\mathrm{HCl}, 2 \%$ SDS, 5\% 2-mercaptoethanol, 13\% glycerol, and $0.013 \%$ bromophenol blue loaded on to a $9 \%$ SDS-polyacrylamide gel and separated by electrophoresis. The protein was transferred to a polyvinylidene difluoride membrane. Membranes were incubated with primary antibody overnight at $4{ }^{\circ} \mathrm{C}$. After washing with Trisbuffered saline (TBS) buffer, the membrane was reincubated with secondary antibody for $1 \mathrm{~h}$. The primary antibodies were pAkt (Ser473 and Thr308), Akt (Cell Signaling Technology), pGSK3 $\beta$ (Ser9) (Cell Signaling Technology), GSK3 $\beta$ (BD Transduction Laboratories, San Jose, CA, USA), and $\gamma$-tubulin (Sigma-Aldrich). The secondary antibodies were anti-rabbit, anti-goat, and anti-mouse.

\section{Measurement of insulin levels in pancreatic tissue}

All of the mice were fasted for $8 \mathrm{~h}$. Their pancreatic tissues were collected and weighed, and $90 \%$ of each pancreatic tissue specimen was prepared for the measurement of insulin content. The remaining $10 \%$ was fixed with formalin and processed for histologic examination.
The pancreatic tissues were homogenized in acid ethanol (75\% ethanol, $1.5 \% \mathrm{HCl}$ in distilled water), and the supernatant was collected from day 1 to day 4 and then sonicated on day 4 . Insulin content was determined by an insulin RIA kit (LINCO Research), and the raw data were transformed using the following calculation: insulin dose $(\mathrm{ng} / \mathrm{ml}) \times$ dilution factor $\times$ total medium volume $(\mathrm{ml}) \times(90 \%$ weight of the pancreatic tissue/total pancreatic tissue weight).

\section{Evaluation of $\beta$ cell mass and islet morphology}

Histologic examination was performed for all five mice in each group. All of the formalin-fixed tissues were embedded in paraffin and stained with hematoxylin and eosin for further review. After deparaffinizing and rehydrating the tissues, immunohistochemistry was performed with polyclonal anti-insulin antibody (Cell Signaling Technology) to identify the $\beta$ cells. Islet mass was measured by a computer-assisted point-counting method on an Axio Observer microscope (Carl Zeiss, Oberkochen, Germany) connected to a computer system running AxioVision 4.7 software (Carl Zeiss). First, a low-magnification view $(40 \times)$ of the whole pancreas was taken for each mouse, and then the images were overlaid on a grid that consisted of 450 points. The islet mass was calculated by dividing the total number of points on the islet cells by the total number of points on all of the pancreatic tissues.

For transmission electron microscopic examination, pancreatic tissues immersed in $2.5 \%$ glutaraldehyde were post-fixed in $1 \%$ osmium tetroxide in $0.1 \mathrm{M}$ phosphate or cacodylate buffer at $\mathrm{pH} 7.2$ for $1.5 \mathrm{~h}$. The tissues were then washed with water, dehydrated in an increasing series of ethanol (50, 60, 70, 80, 90, and 100\%), and immersed in propylene oxide (Acros Organics, Morris Plains, NJ, USA) and EPON epoxy resin (Electron Microscopy Polysciences, Hatfield, PA, USA). Epoxy resin-embedded samples were then placed in a capsule and polymerized for $12 \mathrm{~h}$ at $38^{\circ} \mathrm{C}$ and for $48 \mathrm{~h}$ at $60^{\circ} \mathrm{C}$. The samples were then cut into $50 \mu \mathrm{m}$ ultrathin slices by an ultramicrotome (RMC MT-XL RMC products, Tucson, AZ, USA) and were stained with $4 \%$ uranyl acetate and $4 \%$ lead citrate. The structures were examined by transmission electron microscopy $(15000 \times$ and $50000 \times$ magnification).

\section{Statistical analysis}

Statistical analysis was performed by non-parametric analysis with Mann-Whitney and Kruskal-Wallis tests. A $P$ value of $<0.05$ indicated statistical significance.

Published by Bioscientifica Ltd. 


\section{Results}

\section{Long-term exposure to BPA does not increase body weight or fat mass in growing mice}

Body weight did not differ according to BPA treatment, either with a CD $(29.7 \pm 0.7$ vs $28.6 \pm 0.6 \mathrm{~g})$ or an HFD $(45.3 \pm 0.8$ vs $43.6 \pm 1.4 \mathrm{~g}$ ) (Fig. $1 \mathrm{~A}$ and $\mathrm{B}$ ). Among the CD-fed mice, the percentage of WAT weight $(3.5 \pm 0.8$ vs $2.3 \pm 0.7 \%, P=0.004)$ and percentage of body fat $(30.0 \pm 1.5$ vs $21.4 \pm 3.4 \%, P=0.001)$ were lower in those that were exposed to BPA (Fig. 1C and D). However, among the HFD-fed mice, the percentage of WAT weight and percentage of body fat were not significantly different with or without exposure to BPA (percentage of WAT weight $5.2 \pm 1.2$ vs $4.7 \pm 1.3 \%$; percentage of body fat $56.0 \pm 2.7$ vs $52.4 \pm 3.8 \%$; Fig. $1 C$ and D). Exposure to BPA did not affect the intake of either CD $(11.53 \pm 0.27$ vs $11.66 \pm 1.32 \mathrm{kcal} / \mathrm{mouse}$ per day in the 12 -weeks treated condition, $P=0.29)$ or HFD $(11.82 \pm 0.20$ vs $10.46 \pm 2.83 \mathrm{kcal} / \mathrm{mouse}$ per day in the 12 -weeks treated condition, $P=0.69)$.

\section{Long-term exposure to BPA induces glucose intolerance in HFD-fed mice}

The results of the IPGTTs showed that mice that received an HFD and BPA exhibited a significantly larger area under the IPGTT curve than that of mice that received an HFD
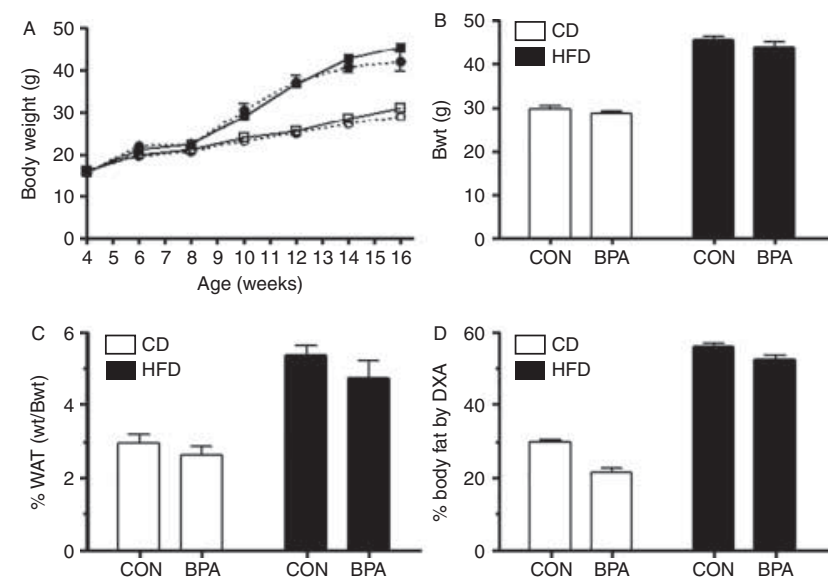

Figure 1

Long-term exposure to bisphenol $A$ in growing mice had no effect on body weight or fat mass. (A) Growth curves in mice that received standard chow $\operatorname{diet}(C D)$ (open circle), $C D$ + bisphenol $A$ (BPA) (open square), high-fat diet (HFD) (filled circle), or HFD + BPA (filled square). (B) Body weight.

(C) Percentage of white adipose tissue (WAT). (D) Percentage of body fat. Data are presented as means \pm S.E.M. Bwt, body weight; CON, control; BPA, bisphenol A; DXA, dual-energy X-ray absorptiometry. only $(119.9 \pm 16.8$ vs $97.9 \pm 18.2 \mathrm{~mm} / \mathrm{min}, \quad P=0.027$; Fig. 2A). Fasting serum insulin levels in mice that received an HFD and BPA tended to increase, but the findings were not statistically significant $(0.32 \pm 0.04$ vs $0.30 \pm$ $0.00 \mathrm{ng} / \mathrm{ml}$ in CD-fed mice; $0.44 \pm 0.14$ vs $0.52 \pm$ $0.29 \mathrm{ng} / \mathrm{ml}$ in HFD-fed mice; Fig. 2B).

\section{Long-term exposure to BPA impairs insulin signaling}

Serum insulin levels tended to increase in mice that received an HFD and BPA, but the findings were not statistically significant. Therefore, we evaluated the phosphorylation status of Akt, an important factor in the insulin signaling pathway, to determine whether BPA-induced glucose intolerance was related to insulin resistance. Interestingly, treatment with BPA reduced Akt phosphorylation at position Thr308 in skeletal muscle after insulin stimulation (Fig. 3A and B). The phosphorylation of glycogen synthase kinase $3 \beta$ (GSK3 $\beta$ ), the downstream signaling molecule of Akt, at Ser9 also significantly decreased in the skeletal muscles of mice that received an HFD and BPA (Fig. 3C and D). However, there were no significant changes in Akt phosphorylation in hepatic or adipose tissue after BPA treatment (data not shown). The hepatic expression of PEPCK and G6Pase, key enzymes of gluconeogenesis, did not change after treatment with BPA (Supplementary Fig. 1A, see section on supplementary data given at the end of this article). In addition, no changes were observed in the expression of phosphofructokinase (PFK) or glycogen synthase (GS) in skeletal muscle after treatment with BPA (Supplementary Fig. 1B). To determine the mechanism by which BPA induces insulin resistance in skeletal muscle, we measured serum adiponectin, IL6, and TNF $\alpha$ levels. Serum adiponectin levels decreased after treatment with BPA, but serum IL6 and TNF $\alpha$ levels increased; however, these differences did not reach statistical significance (Fig. 4).

\section{Long-term exposure to BPA does not affect insulin secretion from $\beta$ cells}

To determine whether BPA induces glucose intolerance by inducing islet cell dysfunction in addition to peripheral insulin resistance in HFD-fed mice, we examined the islet area and morphology as well as the functional insulin secretion of mouse $\beta$ cells. The percentage of the islet area was calculated by dividing the islet area by the pancreatic area. The percentage of the islet area and pancreatic insulin content did not differ between the mice that received an HFD and BPA and those that received an HFD

Published by Bioscientifica Ltd. 

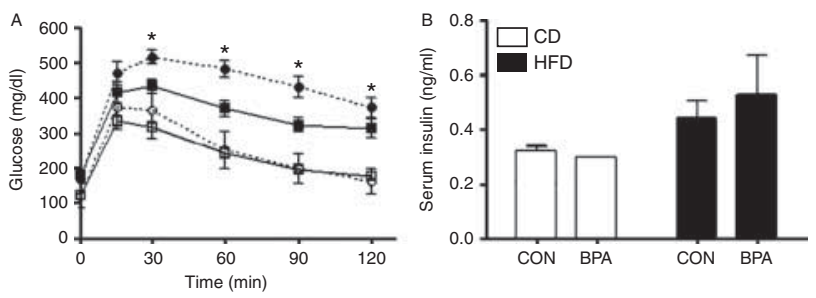

Figure 2

Long-term exposure to bisphenol A induced glucose intolerance in mice that received a high-fat diet (HFD). (A) Intraperitoneal glucose tolerance tests (IPGTTs) (D-glucose: $2 \mathrm{~g} / \mathrm{kg}$ body weight) were performed in 16- to 18week-old male mice that received standard chow diet (CD) (open circle), $\mathrm{CD}+$ bisphenol A (BPA) (open square), HFD (filled circle), or HFD + BPA (filled square). (B) Fasting insulin levels. Data are presented as means \pm S.E.M. ${ }^{*} P<0.05$. CON, control; BPA, bisphenol A.

only (Fig. 5A and B). There were also no significant differences in the morphology or number of islet cells or mitochondria, as examined by electron microscopy in the pancreas, between the mice that received an HFD and BPA and those that received an HFD only (Fig. 5C and D).

\section{Discussion}

In the present study, long-term oral exposure to an HFD and BPA induced glucose intolerance and insulin resistance in growing mice. This effect was not associated with obesity or body adiposity. Treatment with BPA for 12 weeks reduced Akt phosphorylation in skeletal muscle, but neither gluconeogenic hepatic gene expression nor islet cell function was altered. BPA-induced skeletal insulin resistance might be related to changes in serum adipocytokines; serum adiponectin levels were decreased and serum IL6 and $\mathrm{TNF} \alpha$ levels were increased after treatment with BPA, although these changes were not statistically significant.

The two major pathophysiologies of type 2 diabetes mellitus are increased insulin resistance and decreased insulin secretion. In the present study, we first demonstrated that long-term oral exposure to BPA induced glucose intolerance after the neonatal period by increasing insulin resistance in a manner that was not related to $\beta$ cell dysfunction. These findings are consistent with previously published epidemiologic data (Lang et al. 2008, Shankar \& Teppala 2011, Wang et al. 2012) and animal studies (Alonso-Magdalena et al. 2006, Wei et al. 2011, Batista et al. 2012). In two large epidemiologic studies, urinary BPA level was positively associated with type 2 diabetes mellitus (Shankar \& Teppala 2011) and with obesity and insulin resistance (Wang et al. 2012). BPA has been shown to impair the structure and function of hepatic mitochondria and increases the hepatic levels of malondialdehyde, IL6, and
TNF $\alpha$ (Moon et al. 2012). Inflammation plays a key role in the development of insulin resistance, and the IкB kinase- $\beta$ (IKK $\beta$ )/NF- $\mathrm{KB}$ pathway in particular is a molecular mediator of insulin resistance (Shoelson et al. 2003, 2006). Elevated levels of inflammatory cytokines, such as IL6 and TNF $\alpha$, are known to induce the c-Jun NH2-terminal kinase (JNK) and/or IKK $\beta$ pathways. IKK $\beta$ and JNK are well-known serine kinases that phosphorylate IRS1 at serine residues, which results in decreased insulin signaling (Kim et al. 2008, Muoio \& Newgard 2008, Samuel \& Shulman 2012). In the present study, serum IL6 and TNF $\alpha$ levels tended to increase after treatment with BPA, but the increase did not reach statistical significance, possibly because of individual variations between animals (as are commonly observed in in vivo experiments) or because of limited cytokine measuring points after treatment with BPA. In our previous experiment, short-term exposure to BPA increased serum IL6 and TNF $\alpha$ over $6 \mathrm{~h}$, and these elevations were normalized within $24 \mathrm{~h}$ (Moon et al. 2012). In the present experiment, we measured inflammatory cytokine levels at baseline and after 12 weeks of treatment with BPA. Therefore, we might have been unable to detect the maximal changes in these cytokines.
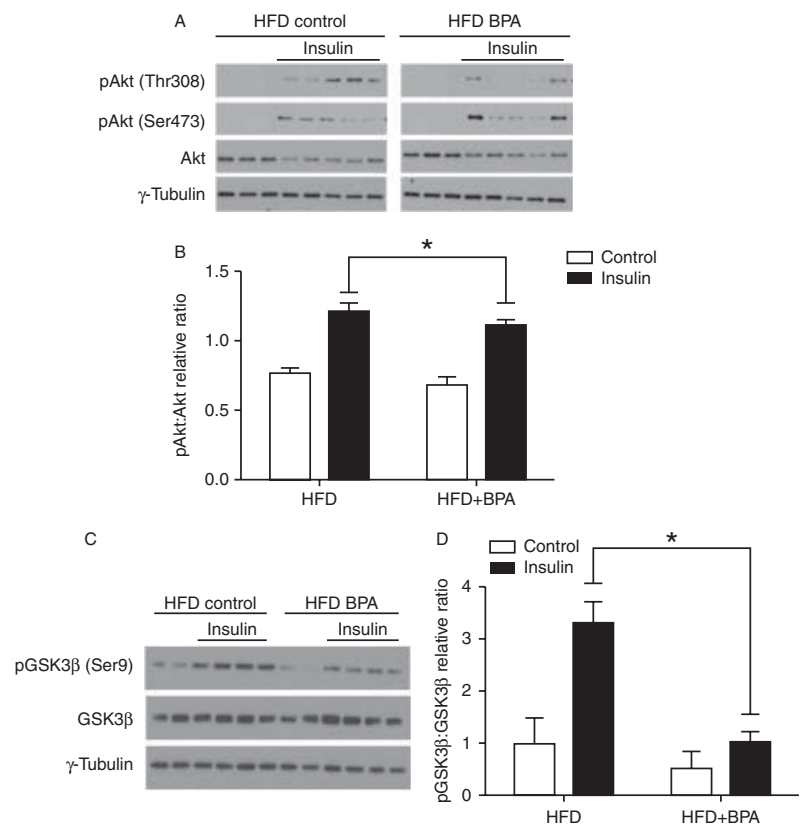

Figure 3

Long-term exposure to bisphenol A impaired insulin signaling in skeletal muscle. (A) Protein analysis of Akt phosphorylation at positions Thr308 and Ser473 in skeletal muscle. (B) Densitometry of Akt phosphorylation at position Thr308. ${ }^{*} P<0.05$. (C) Protein analysis of GSK3 $\beta$ protein levels and its phosphorylation at position Ser9 in skeletal muscle. (D) Densitometry of GSK3 $\beta$ phosphorylation at position Ser9. ${ }^{*} P<0.05$. HFD, high-fat diet; BPA, bisphenol A.

Published by Bioscientifica Ltd. 

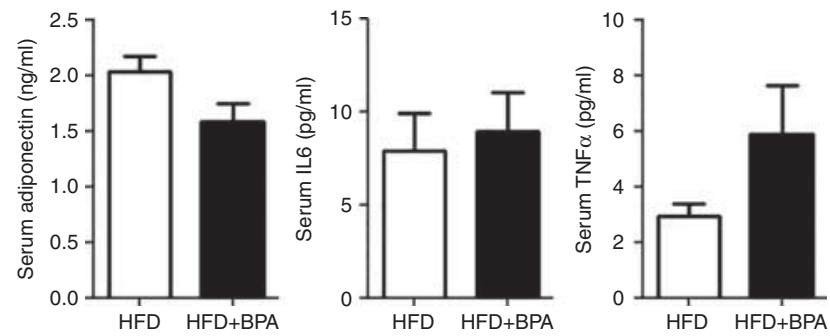

Figure 4

Bisphenol A tended to decrease serum adiponectin levels and increase serum interleukin 6 (IL6) and tumor necrosis factor $\alpha$ (TNF $\alpha$ ) levels. (A) Serum adiponectin levels. (B) Serum IL6 levels. (C) Serum TNF $\alpha$ levels. Data are presented as means \pm s.E.M. HFD, high-fat diet; BPA, bisphenol A.

The inflammatory cytokines IL6 and TNF $\alpha$ are wellknown adipocytokines. In addition to inflammation and/or oxidative stress, alterations in adiposity and/or the production of adipocytokines, such as adiponectin, $\mathrm{TNF} \alpha$, IL6, and leptin, are believed to affect insulin resistance. Perinatal exposure to BPA induces body weight gain in a dose-dependent manner, especially in female rodents, even in later life (Rubin \& Soto 2009). This trend could be caused by the effects of BPA on adipocyte differentiation and lipid accumulation (Ben-Jonathan et al. 2009, Rubin \& Soto 2009). We therefore investigated the changes in adiposity and adipocytokines, but exposure to BPA did not induce weight gain to a greater extent than the control treatments did, which is consistent with a report by Batista et al. (2012). However, changes in adipocytokines may play important roles in the development of BPA-related insulin resistance in the postnatal period or adulthood; interestingly, we found that serum adiponectin levels tended to decrease after treatment with BPA, whereas serum IL6 and TNF $\alpha$ levels tended to increase. Although we could not demonstrate the direct impact of BPA on adipocytokine secretion from WAT, the altered serum adipocytokine levels might be important in BPA-related insulin resistance.

When insulin resistance develops, insulin signaling through IRS1 and Akt is attenuated. BPA has been shown to cause hyperinsulinemia and insulin resistance through glucose or insulin tolerance tests (ITTs; Alonso-Magdalena et al. 2006, 2010, Batista et al. 2012). However, there are limited data on the effects of BPA on insulin signaling. In the present study, we found that BPA decreased Akt phosphorylation in skeletal muscle in vivo. Our results are consistent with a recent study in which BPA was shown to impair insulinstimulated tyrosine phosphorylation of the insulin receptor $\beta$ subunit and insulin-stimulated Akt phosphorylation on the Thr308 residue in skeletal muscle of adult mice treated with $100 \mu \mathrm{g} / \mathrm{kg}$ BPA subcutaneously for 8 days (Batista et al. 2012). The authors also noted a lower BPA-induced effect and decreased insulin-stimulated tyrosine phosphorylation of the insulin receptor $\beta$ subunit in the liver. However, in the present study, we did not detect any significant changes in Akt phosphorylation in hepatic or adipose tissue after BPA treatment. Another study reported that $24 \mathrm{~h}$ of treatment with BPA decreased the level of Akt and Akt phosphorylation in 3T3-L1 adipocytes by 46 and 29\% respectively (Kidani et al. 2010). In the present study, we also examined the effect of BPA treatment on GSK3 $\beta$ phosphorylation in skeletal muscle and confirmed that BPA decreased GSK3 $\beta$ phosphorylation at Ser9, which thereby increased the activity of GSK3 $\beta$ and insulin resistance. Although the evidence is still not sufficient, based on the results of the present study and others, BPA appears to cause insulin resistance by disrupting insulin signaling.

We performed an in vitro study to investigate whether BPA can directly induce insulin resistance. However, BPA treatment did not significantly affect 2-deoxyglucose
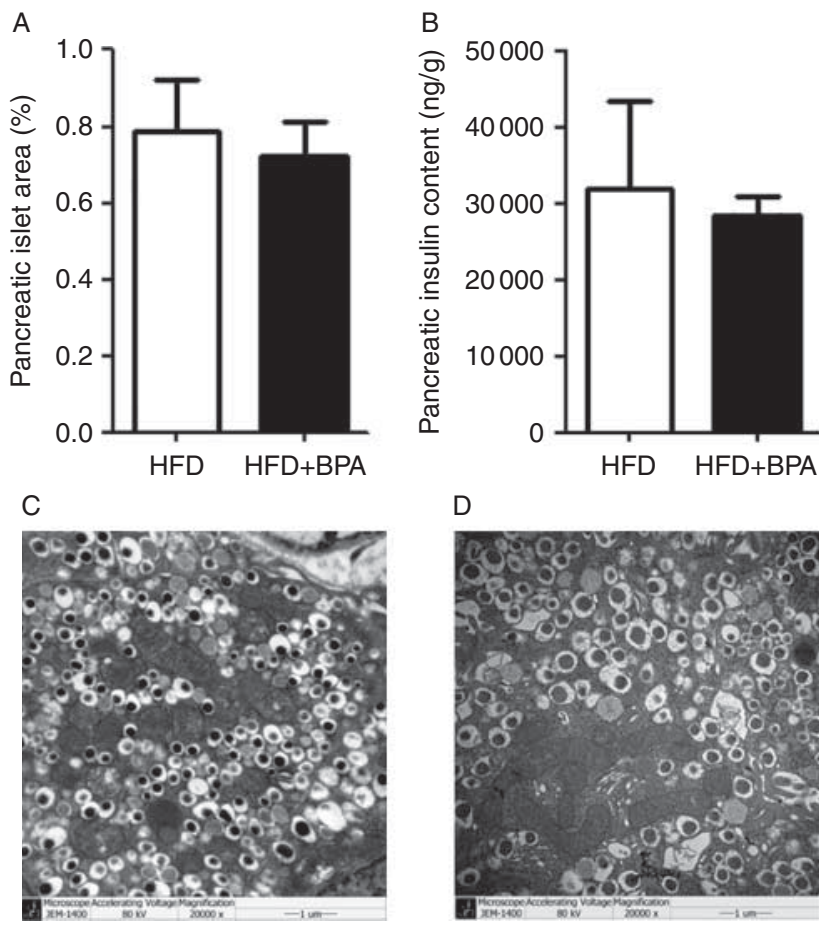

\section{Figure 5}

Long-term exposure to bisphenol A did not induce any detrimental changes in the islet cell area or morphology or the insulin content of $\beta$ cells. (A) Percentage of islet cell area. (B) Percentage of insulin content in pancreatic tissue. Data are presented as means \pm s.E.M. (C) Pancreatic islet cell morphology by electron microscopy in mice fed a high-fat diet (HFD) only (50 000 $\times$ magnification). (D) Pancreatic islet cell morphology in mice fed an HFD and bisphenol A (BPA) (50 000 $\times$ magnification).

Published by Bioscientifica Ltd. 
uptake and Akt phosphorylation in L6 cells (data not shown). These results suggest that BPA might induce skeletal insulin resistance not at the molecular level but rather by altering serum adipocytokines as described earlier in the present study.

We investigated the islet area and morphology as well as the insulin secretion of $\beta$ cells and did not find any differences in the percentage of the islet area or pancreatic insulin content between treatment with BPA and controls. Moreover, there were no significant differences in pancreatic islet morphology as examined by electron microscopy. Therefore, glucose intolerance caused by long-term oral exposure to BPA might be mainly induced by insulin resistance, not by impaired insulin secretion, although there have been some reports that BPA alters oxidative stress or insulin secretion in islet cells (AlonsoMagdalena et al. 2006, 2010). In the present study, because we did not perform an ITT, which is a more accurate method of measuring insulin sensitivity directly, it is difficult to precisely address the issue of insulin secretion in the development of glucose intolerance at this time.

Although our chosen animal models were C57BL/6 male mice fed with HFD, treatment with BPA has also consistently been shown to induce insulin resistance in various other animal models, such as male Swiss albino OF1 mice (Alonso-Magdalena et al. 2006, Batista et al. 2012), CD-1 mice, HFD wistar rats (Wei et al. 2014), and Watanabe heritable hyperlipidemic rabbits (Fang et al. 2015). Therefore, it is quite likely that treatment with BPA would also induce increased insulin resistance in other insulinresistant animal models, such as ob/ob or db/db mice.

The strengths of the present study include the long duration (12 weeks), the route of exposure (oral), and the timing of exposure (during the postnatal period). Although the mouse life cycle does not exactly replicate a normal human life, humans seem to be continually exposed to BPA throughout their lives. In the present study, we wanted to investigate the effects of long-term ingestion of BPA, which is the main route of exposure in adulthood. Most in vitro studies in adult mice have used more than $100 \mu \mathrm{g} / \mathrm{kg}$ BPA per day, but in the present study, we used $50 \mu \mathrm{g} / \mathrm{kg}$ per day, which is the tolerable daily intake dose (EFSA 2008, USFDA 2008, USEPA 2010).

We need to consider the non-monotonic dose-response relationship with regards to the effects of BPA. High-fat-fed offspring that were perinatally exposed to $50 \mu \mathrm{g} / \mathrm{kg}$ BPA per day were shown to have dysmetabolic phenotypes such as obesity, dyslipidemia, hyperleptindemia, hyperglycemia, hyperinsulinemia, and glucose intolerance (Wei et al. 2011). However, no adverse effect of perinatal BPA exposure at the increased concentrations of 250 and $1250 \mu \mathrm{g} / \mathrm{kg}$ per day was observed. In an in vitro study where concentrations ranging from 0 to $100 \mathrm{nM}$ BPA were measured, $1 \mathrm{nM}$ BPA induced the highest level of suppressed adiponectin release from adipose depots and the highest mitogenic capacity in human prostate cancer cells (Wetherill et al. 2002). Exposure to BPA within TDI could be harmful, so more research is needed to determine safer dose exposures.

In conclusion, long-term oral exposure to BPA induced glucose intolerance and insulin resistance in growing mice by disrupting Akt phosphorylation in skeletal muscle and by decreasing adiponectin secretion. These results suggest that not only perinatal but also postnatal and adult exposure to BPA induces insulin resistance and possibly type 2 diabetes mellitus.

\section{Supplementary data}

This is linked to the online version of the paper at http://dx.doi.org/10.1530/ JOE-14-0714.

\section{Declaration of interest}

The authors declare that there is no conflict of interest that could be perceived as prejudicing the impartiality of the research reported.

\section{Funding}

This work was supported by the National Research Foundation of the Ministry of Education, Science and Technology of Korea (grant number 2010-0023068).

\section{References}

Alonso-Magdalena P, Morimoto S, Ripoll C, Fuentes E \& Nadal A 2006 The estrogenic effect of bisphenol A disrupts pancreatic $\beta$-cell function in vivo and induces insulin resistance. Environmental Health Perspectives 114 106-112. (doi:10.1289/ehp.8451)

Alonso-Magdalena P, Vieira E, Soriano S, Menes L, Burks D, Quesada I \& Nadal A 2010 Bisphenol A exposure during pregnancy disrupts glucose homeostasis in mothers and adult male offspring. Environmental Health Perspectives 118 1243-1250. (doi:10.1289/ehp.1001993)

Asahi J, Kamo H, Baba R, Doi Y, Yamashita A, Murakami D, Hanada A \& Hirano T 2010 Bisphenol A induces endoplasmic reticulum stressassociated apoptosis in mouse non-parenchymal hepatocytes. Life Sciences 87 431-438. (doi:10.1016/j.lfs.2010.08.007)

Batista TM, Alonso-Magdalena P, Vieira E, Amaral ME, Cederroth CR, Nef S, Quesada I, Carneiro EM \& Nadal A 2012 Short-term treatment with bisphenol-A leads to metabolic abnormalities in adult male mice. PLoS ONE 7 e33814. (doi:10.1371/journal.pone.0033814)

Ben-Jonathan N, Hugo ER \& Brandebourg TD 2009 Effects of bisphenol A on adipokine release from human adipose tissue: implications for the metabolic syndrome. Molecular and Cellular Endocrinology 304 49-54. (doi:10.1016/j.mce.2009.02.022)

Bi S, Chen J, Behles RR, Hyun J, Kopin AS \& Moran TH 2007 Differential body weight and feeding responses to high-fat diets in rats and mice lacking cholecystokinin 1 receptors. American Journal of Physiology 
Regulatory, Integrative and Comparative Physiology 293 R55-R63. (doi:10.1152/ajpregu.00002.2007)

Bindhumol V, Chitra KC \& Mathur PP 2003 Bisphenol A induces reactive oxygen species generation in the liver of male rats. Toxicology 188 117-124. (doi:10.1016/S0300-483X(03)00056-8)

Brotons JA, Olea-Serrano MF, Villalobos M, Pedraza V \& Olea N 1995 Xenoestrogens released from lacquer coatings in food cans. Environmental Health Perspectives 103 608-612. (doi:10.1289/ehp.95103608)

EFSA 2008 Statement of EFSA on a study associating bisphenol A with medical disorders. EFSA Journal 838 1-3.

Fang C, Ning B, Waqar AB, Niimi M, Li S, Satoh K, Shiomi M, Ye T, Dong S \& Fan J 2015 Bisphenol A exposure induces metabolic disorders and enhances atherosclerosis in hyperlipidemic rabbits. Journal of Applied Toxicology [in press]. (doi:10.1002/jat.3103)

Hiroi H, Tsutsumi O, Momoeda M, Tatai Y, Osuga Y \& Taketani Y 1999 Differential interactions of bisphenol A and $17 \beta$-estradiol with estrogen receptor $\alpha(\mathrm{ER} \alpha)$ and ER $\beta$. Endocrine Journal 46 773-778. (doi:10.1507/endocri.46.773)

Howdeshell KL, Hotchkiss AK, Thayer KA, Vandenbergh JG \& vom Saal FS 1999 Environmental toxins - exposure to bisphenol A advances puberty. Nature 401 763-764. (doi:10.1038/44517)

Hugo ER, Brandebourg TD, WooJG, Loftus J, Alexander JW \& Ben-Jonathan N 2008 Bisphenol A at environmentally relevant doses inhibits adiponectin release from human adipose tissue explants and adipocytes. Environmental Health Perspectives 116 1642-1647. (doi:10.1289/ehp.11537)

Kidani T, Kamei S, Miyawaki J, Aizawa J, Sakayama K \& Masuno H 2010 Bisphenol A downregulates Akt signaling and inhibits adiponectin production and secretion in 3T3-L1 adipocytes. Journal of Atherosclerosis and Thrombosis 17 834-843. (doi:10.5551/jat.4051)

Kim JA, Wei Y \& Sowers JR 2008 Role of mitochondrial dysfunction in insulin resistance. Circulation Research 102 401-414. (doi:10.1161/ CIRCRESAHA.107.165472)

Kurosawa T, Hiroi H, Tsutsumi O, Ishikawa T, Osuga Y, Fujiwara T, Inoue S, Muramatsu M, Momoeda M \& Taketani Y 2002 The activity of bisphenol A depends on both the estrogen receptor subtype and the cell type. Endocrine Journal 49 465-471. (doi:10.1507/endocrj.49.465)

Lang IA, Galloway TS, Scarlett A, Henley WE, Depledge M, Wallace RB \& Melzer D 2008 Association of urinary bisphenol A concentration with medical disorders and laboratory abnormalities in adults. JAMA $\mathbf{3 0 0}$ 1303-1310. (doi:10.1001/jama.300.11.1303)

Masuno H, Kidani T, Sekiya K, Sakayama K, Shiosaka T, Yamamoto H \& Honda K 2002 Bisphenol A in combination with insulin can accelerate the conversion of 3T3-L1 fibroblasts to adipocytes. Journal of Lipid Research 43 676-684.

Masuno H, Iwanami J, Kidani T, Sakayama K \& Honda K 2005 Bisphenol A accelerates terminal differentiation of 3T3-L1 cells into adipocytes through the phosphatidylinositol 3-kinase pathway. Toxicological Sciences 84 319-327. (doi:10.1093/toxsci/kfi088)

Moon MK, Kim MJ, Jung IK, Koo YD, Ann HY, Lee KJ, Kim SH, Yoon YC, Cho BJ, Park KS et al. 2012 Bisphenol A impairs mitochondrial function in the liver at doses below the no observed adverse effect level. Journal of Korean Medical Science 27 644-652. (doi:10.3346/jkms.2012.27.6.644)

Muoio DM \& Newgard CB 2008 Mechanisms of disease: molecular and metabolic mechanisms of insulin resistance and $\beta$-cell failure in type 2 diabetes. Nature Reviews Molecular Cell Biology 9 193-205. (doi:10.1038/ nrm2327)

Nadal A, Ropero AB, Laribi O, Maillet M, Fuentes E \& Soria B 2000 Nongenomic actions of estrogens and xenoestrogens by binding at a plasma membrane receptor unrelated to estrogen receptor $\alpha$ and estrogen receptor $\beta$. PNAS 97 11603-11608. (doi:10.1073/pnas.97.21.11603)
Nakagawa Y \& Tayama S 2000 Metabolism and cytotoxicity of bisphenol A and other bisphenols in isolated rat hepatocytes. Archives of Toxicology 74 99-105. (doi:10.1007/s002040050659)

Ohlstein JF, Strong AL, McLachlan JA, Gimble JM, Burow ME \& Bunnell BA 2014 Bisphenol A enhances adipogenic differentiation of human adipose stromal/stem cells. Journal of Molecular Endocrinology 53 345-353. (doi:10.1530/JME-14-0052)

Olea N, Pulgar R, Perez P, Olea-Serrano F, Rivas A, Novillo-Fertrell A, Pedraza V, Soto AM \& Sonnenschein C 1996 Estrogenicity of resinbased composites and sealants used in dentistry. Environmental Health Perspectives 104 298-305. (doi:10.1289/ehp.96104298)

Rubin BS \& Soto AM 2009 Bisphenol A: perinatal exposure and body weight. Molecular and Cellular Endocrinology 304 55-62. (doi:10.1016/j. mce.2009.02.023)

Rubin BS, Murray MK, Damassa DA, King JC \& Soto AM 2001 Perinatal exposure to low doses of bisphenol A affects body weight, patterns of estrous cyclicity, and plasma LH levels. Environmental Health Perspectives 109 675-680. (doi:10.1289/ehp.01109675)

Ryan KK, Haller AM, Sorrell JE, Woods SC, Jandacek RJ \& Seeley RJ 2010 Perinatal exposure to bisphenol-A and the development of metabolic syndrome in CD-1 mice. Endocrinology 151 2603-2612. (doi:10.1210/ en.2009-1218)

Samuel VT \& Shulman GI 2012 Mechanisms for insulin resistance: common threads and missing links. Cell 148 852-871. (doi:10.1016/j. cell.2012.02.017)

Shankar A \& Teppala S 2011 Relationship between urinary bisphenol A levels and diabetes mellitus. Journal of Clinical Endocrinology and Metabolism 96 3822-3826. (doi:10.1210/jc.2011-1682)

Shoelson SE, Lee J \& Yuan M 2003 Inflammation and the IKK $\beta / \mathrm{I} \kappa$ B/NF- $\kappa$ B axis in obesity- and diet-induced insulin resistance. International Journal of Obesity 27 S49-S52. (doi:10.1038/sj.ijo.0802501)

Shoelson SE, Lee J \& Goldfine AB 2006 Inflammation and insulin resistance. Journal of Clinical Investigation 116 1793-1801. (doi:10.1172/JCI29069)

Somm E, Schwitzgebel VM, Toulotte A, Cederroth CR, Combescure C, Nef S, Aubert ML \& Huppi PS 2009 Perinatal exposure to bisphenol A alters early adipogenesis in the rat. Environmental Health Perspectives 117 1549-1555. (doi:10.1289/ehp.11342)

USEPA 2010 Bisphenol A action plan. Washington, DC, USA: US Environmental Protection Agency. (available at: http://www.epa.gov/ opptintr/existingchemicals/pubs/actionplans/bpa_action_plan.pdf).

USFDA 2008 Draft assessment of bisphenol A for use in food contact applications. Washington, DC, USA: US Environmental Protection Agency. (available at: http://www.fda.gov/ohrms/dockets/ac/08/briefing/2008-0038b1_01_02_FDA\%20BPA\%20Draft\%20Assessment.pdf)

Wang TG, Li MA, Chen B, Xu M, Xu Y, Huang Y, Lu JL, Chen YH, Wang WQ, Li XY et al. 2012 Urinary bisphenol A (BPA) concentration associates with obesity and insulin resistance. Journal of Clinical Endocrinology and Metabolism 97 E223-E227. (doi:10.1210/jc.2011-1989)

Wei J, Lin Y, Li Y, Ying C, Chen J, Song L, Zhou Z, Lv Z, Xia W, Chen X et al. 2011 Perinatal exposure to bisphenol A at reference dose predisposes offspring to metabolic syndrome in adult rats on a high-fat diet. Endocrinology 152 3049-3061. (doi:10.1210/en.2011-0045)

Wei J, Sun X, Chen Y, Li Y, Song L, Zhou Z, Xu B, Lin Y \& Xu S 2014 Perinatal exposure to bisphenol A exacerbates nonalcoholic steatohepatitis-like phenotype in male rat offspring fed on a high-fat diet. Journal of Endocrinology 222 313-325. (doi:10.1530/JOE-14-0356)

Wetherill YB, Petre CE, Monk KR, Puga A \& Knudsen KE 2002 The xenoestrogen bisphenol A induces inappropriate androgen receptor activation and mitogenesis in prostatic adenocarcinoma cells. Molecular Cancer Therapeutics 1 515-524.

Received in final form 29 April 2015

Accepted 13 May 2015

Accepted Preprint published online 13 May 2015 http://joe.endocrinology-journals.org

DOI: $10.1530 / J O E-14-0714$
(C) 2015 Society for Endocrinology Printed in Great Britain
Published by Bioscientifica Ltd 